\title{
Case study: comparison of air dispersion from solid waste incinerator emission using AERMOD and ISCST3
}

\begin{abstract}
Combustion of municipal solid waste in a solid waste incinerator will generates flue gas emission consist of pollutants that may detrimental to human health. It was intended to observe the dispersion of the pollutants from the chimney of solid waste incinerator of Cameron Highlands using two air dispersion models, AERMOD and ISCST3. This study involves usage of 1 year hourly meteorological data, terrain data, chimney specification and pollutant emission rate as input in both models to predict the pollutants incremental concentration to the surrounding environment. It was found that AERMOD model simulates in a way similar to the real meteorological condition as compared to ISCST3. Higher concentration was predicted nearer to the pollutant source and at sensitive receptors in AERMOD as compared to ISCST3 prediction.
\end{abstract}

Keyword: Air dispersion; AERMOD; ISCST3; Incinerator 